\title{
CUESTIÓN DE GÉNERO: LA DISCRIMINACIÓN DE LAS INVESTIGADORAS EN ESPAÑA
}

D Aldara Cidrás ${ }^{1}$

Laura Camino PlazaII

I Grupo de Investigación Histagra, Universidad de Santiago de Compostela, España; aldara.cidras.fuentes@usc.gal

II Grupo de Investigación Teoría de la Literatura y Literatura Comparada, Universidad de Santiago de Compostela, España; Icaminoplaza@gmail.com

\section{Resumen}

Partiendo de la comparación entre los datos disponibles a nivel estatal y europeo para el periodo 2013-2018, este trabajo revisará las diversas discriminaciones que afectan a las mujeres que trabajan en el sistema de investigación español, en base a tres parámetros de análisis principales: desigualdad, invisibilización y precariedad. Del diálogo entre las fuentes primarias y secundarias se desprenderá una lectura cualitativa de los mismos, que ahondará en las causas y consecuencias psicosociales, económicas e institucionales relacionadas con la discriminación por razón de sexo dentro del sector de investigación. El resultado será mostrar el complejo sistema de opresiones al que se enfrentan las investigadoras españolas como parte de una tendencia global de devaluación del talento femenino.

ESPAÑA • UNIÓN EUROPEA • DISCRIMINACIÓN SEXUAL • ESTUDIOS DE GÉNERO

\section{QUESTÃO DE GÊNERO: A DISCRIMINAÇÃO DAS PESQUISADORAS NA ESPANHA \\ Resumo}

Partindo da comparação entre os dados disponíveis em nível nacional e europeu, no tocante ao período 2013-2018, este artigo verificará as diversas discriminações que afetam as mulheres que trabalham no sistema de pesquisa espanhol, baseando-se em três parâmetros principais de análise: desigualdade, invisibilização e precariedade. $\mathrm{O}$ diálogo entre as fontes primárias e secundárias resultará em uma leitura qualitativa desses parâmetros que aprofundará as causas e consequências psicossociais, econômicas e institucionais relacionadas com a discriminação em função do sexo no setor de pesquisa. $\mathrm{O}$ resultado mostra o complexo sistema de opressões que as pesquisadoras espanholas enfrentam como parte de uma tendência global de desvalorização do talento feminino.

ESPANHA • UNIÃO EUROPEIA • DISCRIMINAÇÃO SEXUAL・ESTUDOS DE GÊNERO 


\title{
A MATTER OF GENDER: SEX DISCRIMINATION AGAINST WOMEN RESEARCHERS IN SPAIN
}

\begin{abstract}
Based on the comparison between the data available at Spanish and European levels for the period 2013-2018, this article will focus on reviewing the several discriminations that affect women researchers in the Spanish academia, articulating the analysis on three primary parameters: inequality, invisibility, and precariousness. A qualitative reading will emerge from the dialogue between the primary and secondary sources, which will delve into the psychosocial, economic, and institutional causes and consequences of sex discrimination within the $\mathrm{R}+\mathrm{D}$ sector. The result will show the complex system of intricate oppressions that Spanish female researchers face as part of a global trend of the devaluation of female talent.
\end{abstract}

SPAIN • EUROPEAN UNION • SEX DISCRIMINATION • GENDER STUDIES

\section{QUESTION DE GENRE : DISCRIMINATION DES CHERCHEUSES EN ESPAGNE}

\section{Résumé}

Ancré sur les données disponibles au niveau national et européen, pour la période 2013-2018, cet article vise à analyser les différentes discriminatio qui affectent les femmes dans le système de recherche espagnol. Il s'appuie sur trois paramètres principaux : l'inégalité, l'invisibilité et la précarité. Le dialogue entre les sources primaires et secondaires mène à une lecture qualitative de ces paramètres visant à approfondir les causes et les conséquences psychosociales, économiques et institutionnelles liées à la discrimination fondée sur le sexe dans le secteur de la recherche. Les résultats confirment le système complexe d'oppression auquel les chercheuses espagnoles sont soumises, suivant la tendance mondiale de dépréciation des talents féminins.

ESPAGNE • UNION EUROPÉENNE • DISCRIMINATION SEXUELLE • ÉTUDES DE GENRE 
por una fuerte desigualdad, manifestada de manera horizontal en la inicua representación femenina dentro de algunas disciplinas, y verticalmente a través de la infrarrepresentación de las mujeres en los puestos de poder, lo que se ha dado en denominar "techo de cristal". De ello se constata la invisibilización sistemática de las mujeres investigadoras y de sus trabajos y aportaciones dentro de las propias instituciones relacionadas con la investigación, así como una constante devaluación social del talento femenino, deficientemente integrado en las políticas públicas, los órganos decisorios o los currículos educativos. La falta de inversión en investigación, unida a la alta competitividad que acucia al sector y la ausencia de medidas efectivas que garanticen la conciliación, tienen consecuencias directas en la situación profesional y personal de las investigadoras, que se ven especialmente afectadas por la precariedad, la temporalidad y el estrés laboral.

Para procurar comprender el intrincado sistema de obstáculos y opresiones que sufren las mujeres investigadoras en España se revela oportuno hacer una lectura comparada de los informes más recientes disponibles, tanto a nivel estatal como europeo, en diálogo con la literatura académica más actualizada en materia de género, igualdad y conciliación. Dado que en las últimas décadas se ha escrito mucho sobre las desigualdades que sufren las mujeres en el ámbito de la investigación, se ha considerado pertinente llevar a cabo una selección de fuentes secundarias en base a los tres ejes temáticos sobre los que se organizará la argumentación de este artículo: desigualdad, invisibilización y precariedad. Por su parte, los datos de los informes aquí considerados han sido extractados siguiendo el mismo enfoque tripartito, para mayor coherencia y equilibrio. El cotejo contrastado de las fuentes primarias se ha revelado eficaz a la hora de paliar los efectos derivados de la gran disparidad de enfoques, metodologías y alcance con la que cada uno de los informes consultados ha sido elaborado por las instituciones y órganos correspondientes.

Aunque el objetivo principal del trabajo es ofrecer una radiografía general sobre la situación inicua de las investigadoras de España respecto de sus pares masculinos, no se obviará la combinación de ejemplos extraídos de un nivel analítico micro -sobre centros de investigación y disciplinas concretas, por ejemplo- y de un nivel macro, a través de la comparación con otros países. En consecuencia, este artículo pretende enriquecer el debate sobre la desigualdad de género en la investigación e ilustrar la complejidad de este fenómeno global mediante la aportación de datos actualizados.

\section{Desigualdades presentes en el sector de la investigación}

En España, las mujeres conforman el principal exponente de talento egresado, tal y como ratifican los últimos datos. Para el curso 2016-2017, las alumnas superaron en todos los indicadores de desempeño académico a sus compañeros varones: tasa de rendimiento, éxito, evaluación, idoneidad, graduación... y menor tasa de abandono tanto en grado como en máster. También muestran una mejor nota media general y son las principales receptoras de becas estatales: ellas obtuvieron un $81,45 \%$ y un $68,42 \%$ de las ayudas para grado y máster, respectivamente, en dicho curso. Además, según la información extraída de la base de datos del Ministerio de Ciencia, Innovación y Universidades (MCIU, 2020) de España, en 2018 fueron mayoría en el total de personas matriculadas y egresadas en grado $(54,87 \%$ y $59,46 \%)$ y máster (54,36\% y 57,01\%). Sin embargo, las mujeres pierden representatividad cuando 
avanzan en la carrera investigadora, lo que en la literatura académica se ha dado en denominar "gráfico tijera”, como vemos en la Gráfica $1:^{1}$
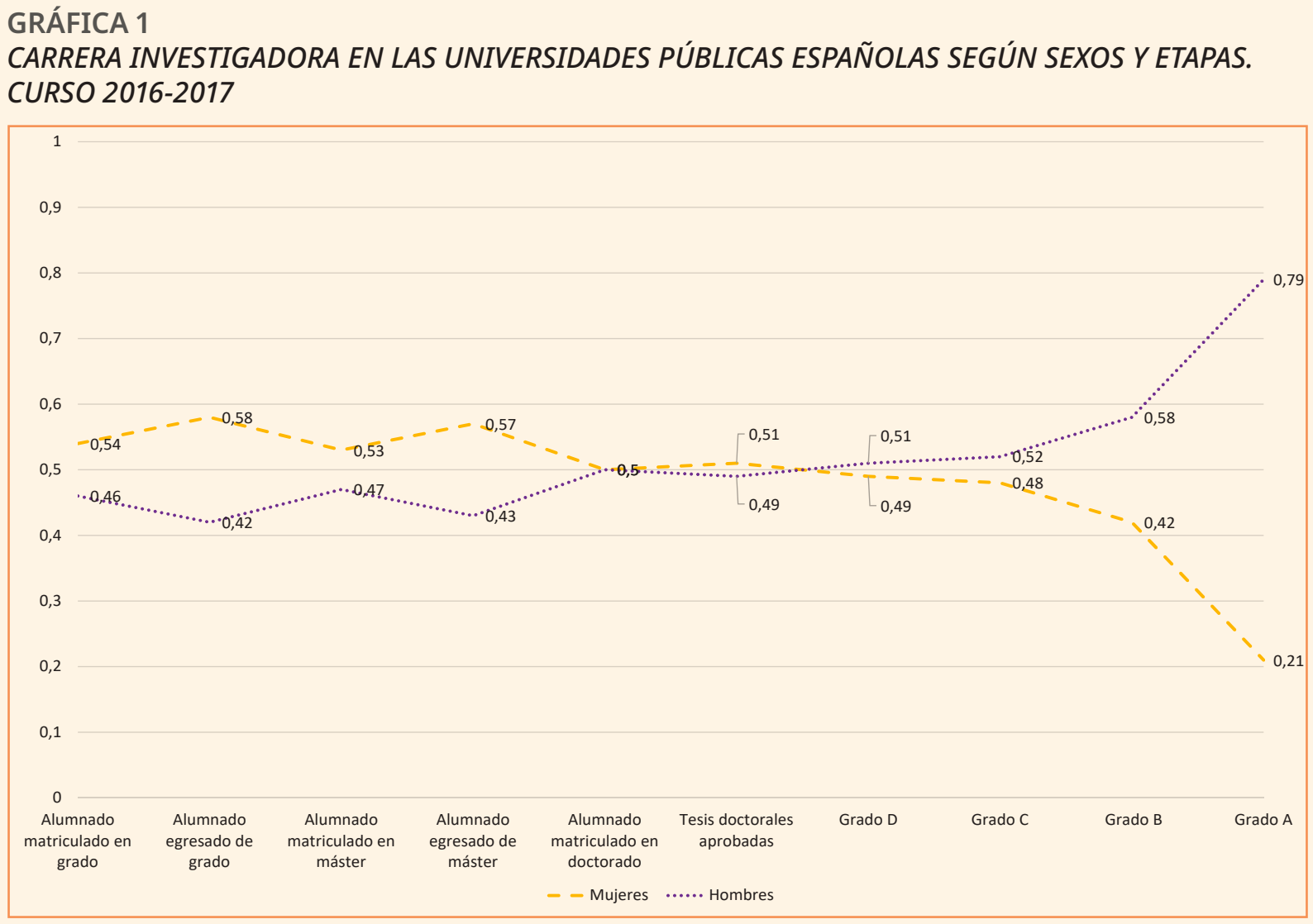

Fuente: Elaboración propia a partir de datos del MCIU (2018, p. 66).

Las mujeres son mayoría durante las etapas académicas formativas. La diferencia se recorta al comienzo de la carrera investigadora -identificada con el doctorado-, igualándose el porcentaje de mujeres y hombres matriculados. Sin embargo, a partir de la defensa de la tesis, las mujeres son paulatinamente excluidas de los puestos de mayor responsabilidad, llegando al extremo de que apenas un $21 \%$ del profesorado universitario con cátedra es mujer. Se produce así una identificación del trabajo más precarizado con el que mayor ocupación femenina tiene, mientras que el de mayor retribución económica y consideración social sigue siendo principalmente masculino, pese a que los datos sobre el talento egresado nos llevarían a esperar lo contrario. En el mercado laboral académico se ha naturalizado una división sexuada no igualitaria del trabajo que perjudica a las mujeres y que no responde a cuestiones de aptitudes, sino que encuentra su raíz en explicaciones sociales que se reproducen en otros entornos laborales.

Esta segregación vertical por sexos, o techo de cristal, actúa de manera conjunta con la segregación horizontal por sexos, la cual provoca que algunos ámbitos del conocimiento, especialmente los relacionados con Ciencias, Tecnología, Ingeniería y Matemáticas (STEM, por sus siglas en inglés) estén muy masculinizados, pero también que otros - como Educación o Salud- se encuentren muy feminizados, de manera acorde al binomio de raíces genérico-sexuales por el que los hombres suelen estar asociados a las tareas de producción y las mujeres a las de cuidados (Sabater, 2014, p. 167).

1 En el organigrama académico español, los grados se corresponden a las siguientes categorías laborales: Grado D = Profesorado Ayudante, Personal Investigador en Formación con contratos de convocatorias competitivas; Grado $C$ = Profesorado Ayudante Doctor (AD), personal contratado del Programa Juan de la Cierva, investigadoras/ es visitantes, otro personal investigador posdoctoral; Grado B = Titularidad de Universidad (TU), Cátedra de Escuela Universitaria, Contratado/a Doctor/a (CD), personal contratado del Programa Ramón y Cajal; Grado A = Cátedra de Universidad (CU). 
Importa resaltar la hipermasculinización de las STEM, en tanto que es la unidad de conocimiento de mayor apoyo e interés tanto público como privado y con mejor empleabilidad general, junto con las Ciencias de la Salud (Pérez \& Aldás, 2020). Los últimos datos ofrecidos por la Conferencia de Rectores de las Universidades Españolas (Crue, 2019, p. 53) apuntan que, en el total de las STEM, solo un 26,82\% de las nuevas matrículas para el curso 2017-2018 pertenecen a mujeres, perpetuando la desigualdad en el seno de uno de los mayores focos de inversión en $\mathrm{I}+\mathrm{D}+\mathrm{i}$. Así, si atendemos a la participación de las mujeres en las matrículas de nuevo ingreso para el curso dado, descubriremos que las carreras con menor porcentaje de alumnas en las universidades públicas presenciales españolas son Ingeniería del Automóvil (5,3\%) o Ingeniería de Computadores (9,7\%) (Crue, 2019, p. 56). Pero, a pesar de suponer una clara minoría, las estadísticas recogidas por el Sistema Universitario de Información Universitaria (Suiu, 2019) confirman que las mujeres muestran mejores tasas de rendimiento que sus compañeros en la rama STEM, con diferencias porcentuales que van desde los 2 puntos en el área de Informática hasta los 6 en la de Ingeniería, Industria y Construcción. En el otro lado de la balanza, los ámbitos de estudio más feminizados en etapa formativa son Educación Infantil (92,7\%), Trabajo Social y Orientación (82\%) y Enfermería y Atención a Enfermos (80,9\%), carreras con una tradicional vinculación a los cuidados (MCIU, 2020).

Numerosos estudios han analizado el componente psicosocial que se esconde tras este tipo de elecciones profesionales, muy condicionadas por los estereotipos de género (López Sáez, 1995; Bian et al., 2017) y sobre las que tienen un grado alto de responsabilidad los diferentes agentes implicados en nuestra socialización a partir de la infancia. Un análisis profundo de la segregación horizontal de género deberá tener en cuenta que las vocaciones, expectativas y decisiones profesionales están influidas por la familia y sus condicionantes socioeconómicos (Sáinz Ibáñez \& Müller, 2017), pero también por el input ejercido por el profesorado de primaria y secundaria (Sáinz Ibáñez \& Meneses, 2018). En este sentido, Subirats Martòri y Brullet Tenas (1988, p. 24) enfatizaron la importancia de analizar el "currículo oculto", es decir, el sistema de valores relacionado con el género que se transmite en la escuela. Las autoras pusieron de manifiesto que ya por aquel entonces la "feminización de la enseñanza" no estaba repercutiendo en un acercamiento a la igualdad, pues “. . . la devaluación social de las mujeres las conduce a ellas mismas a distanciarse de las niñas y a reproducir en su actuación profesional los valores y los estereotipos masculinos, para no mostrarse distintas ni vulnerables" (Subirats Martòri \& Brullet Tenas, 1988, p. 116).

Como el autoconcepto de género se comienza a desarrollar en fases tempranas de la vida humana (Navarro Guzmán \& Casero Martínez, 2012), resulta relevante que tanto en la familia como en la escuela se sigan perpetuando los roles de género por los cuales "las chicas son mejores en áreas tradicionalmente femeninas, como las lenguas, mientras que a los chicos se les considera mejores en diferentes ámbitos tecnológicos y científicos, como, por ejemplo, la física” (Sáinz Ibáñez \& Meneses, 2018, p. 27). Así, es común que las y los jóvenes de España hagan elecciones universitarias y profesionales prototípicas para su género.

Esta disparidad sexuada de base, que se interrelaciona explícitamente con el concepto de "suelo pegajoso"2 (Torres González \& Pau, 2011), se mantiene en las posteriores etapas académicas. $\mathrm{Si}$ atendemos al sexo de las personas que leyeron su tesis en el curso 2018-2019, vuelven a ser las STEM las que tienen un menor porcentaje de mujeres: un 20,93\% en Informática, un 32,19\% en Ingenierías y un 34,38\% en Matemáticas y Estadística (MCIU, 2020). Como consecuencia,

2 La metáfora del suelo pegajoso o sticky floor se relaciona, por efecto espejo, con el techo de cristal, ya que se refiere a todas aquellas barreras sociales e institucionales que atrapan a la mujer en la base de un sistema piramidal y patriarcal como el actual. Entre ellas, destaca la temporalidad y precariedad derivada de la ausencia de posibilidades de ascenso profesional y de medidas de conciliación efectiva. 
las investigadoras STEM tienen mayores dificultades para avanzar en el escalafón académico, lo que implica, por ejemplo, que el área de Ingeniería y Tecnología sea la que menor proporción de mujeres tiene, llegando a un reducidísimo 12\% en la figura de CU para el curso 2016-2017. En contraposición, las CU de Humanidades suponen un también escueto 29\% del total, aunque es el porcentaje de mujeres más elevado de todas las seis grandes áreas -Ciencias Naturales, Ingeniería y Tecnología, Ciencias Médicas y de la Salud, Ciencias Agrícolas, Ciencias Sociales y Humanidades - para dicha categoría laboral, dinámica que también se reproduce a nivel europeo y global.

Se puede constatar, entonces, que la desigualdad de género horizontal convive con otra vertical, también en las carreras cuyas bases están feminizadas. Un trabajo reciente focalizado en el caso de la Facultad de Bellas Artes de la Universidad de Salamanca muestra que desde la creación de la titulación en 1983 hasta el curso académico 2013-2014, las mujeres fueron la mayoría de alumnado egresado, aunque solo suponen un 26,09\% del total del profesorado y están casi excluidas de las categorías laborales más altas: no hay ninguna mujer CU y solo ostentan un tercio de las titularidades (Martín Asensio et al., 2015, p. 380).

La exclusión de las mujeres de los puestos de mayor responsabilidad, retribución salarial y consideración social fue identificada hace más de 20 años con la metáfora del "techo de cristal", introducida por Hymowitz y Schellhardt (1986) para identificar las "barreras invisibles" que bloqueaban el acceso de las mujeres, en el contexto estadounidense, a los puestos de poder en sus respectivas profesiones. Desde entonces, se ha producido mucha bibliografía que trata este fenómeno global y transversal, que afecta también a la $\mathrm{I}+\mathrm{D}+\mathrm{i}$. Una ingente cantidad de investigadoras se ven forzadas a permanecer en puestos laborales inferiores a los que merecerían por sus capacidades y méritos, o incluso a abandonar la carrera académica ante la imposibilidad de seguir avanzando -lo que, en el fondo, constituye una expulsión del sistema-. España es el cuarto país de la Unión Europea (UE) con mayor Índice de Techo de Cristal entre las investigadoras, siendo también uno de los 3 únicos países en los que dicho índice ha aumentado en los últimos años (CE, 2019, p. 124). Pese a haber una mayor concienciación social frente al techo de cristal, la situación de las investigadoras ha empeorado en el tramo 2013-2016, poniendo en entredicho también el tipo de políticas e iniciativas activadas para paliar la situación (Nuño Gómez \& Álvarez Conde, 2017, pp. 291-292).

Para apreciar la interrelación entre la segregación horizontal y la vertical es significativo atender a los datos porcentuales de personal investigador entre el Personal Docente e Investigador (PDI) de las universidades públicas españolas según sexo, área de conocimiento y categoría laboral. Presentamos los datos en dos gráficas diferentes para una mayor claridad, pero superpuestos podríamos ver cómo se produce una gráfica tijera, en la que la evolución negativa de las mujeres como PDI es inversamente proporcional a la hipermasculinización de las categorías de mayor nivel. 
GRÁFICA 2

PORCENTAJE DE MUJERES INVESTIGADORAS EN EL PDI DE LAS UNIVERSIDADES PÚBLICAS ESPAÑOLAS SEGÚN ÁREA Y CATEGORÍA. CURSO 2016-2017

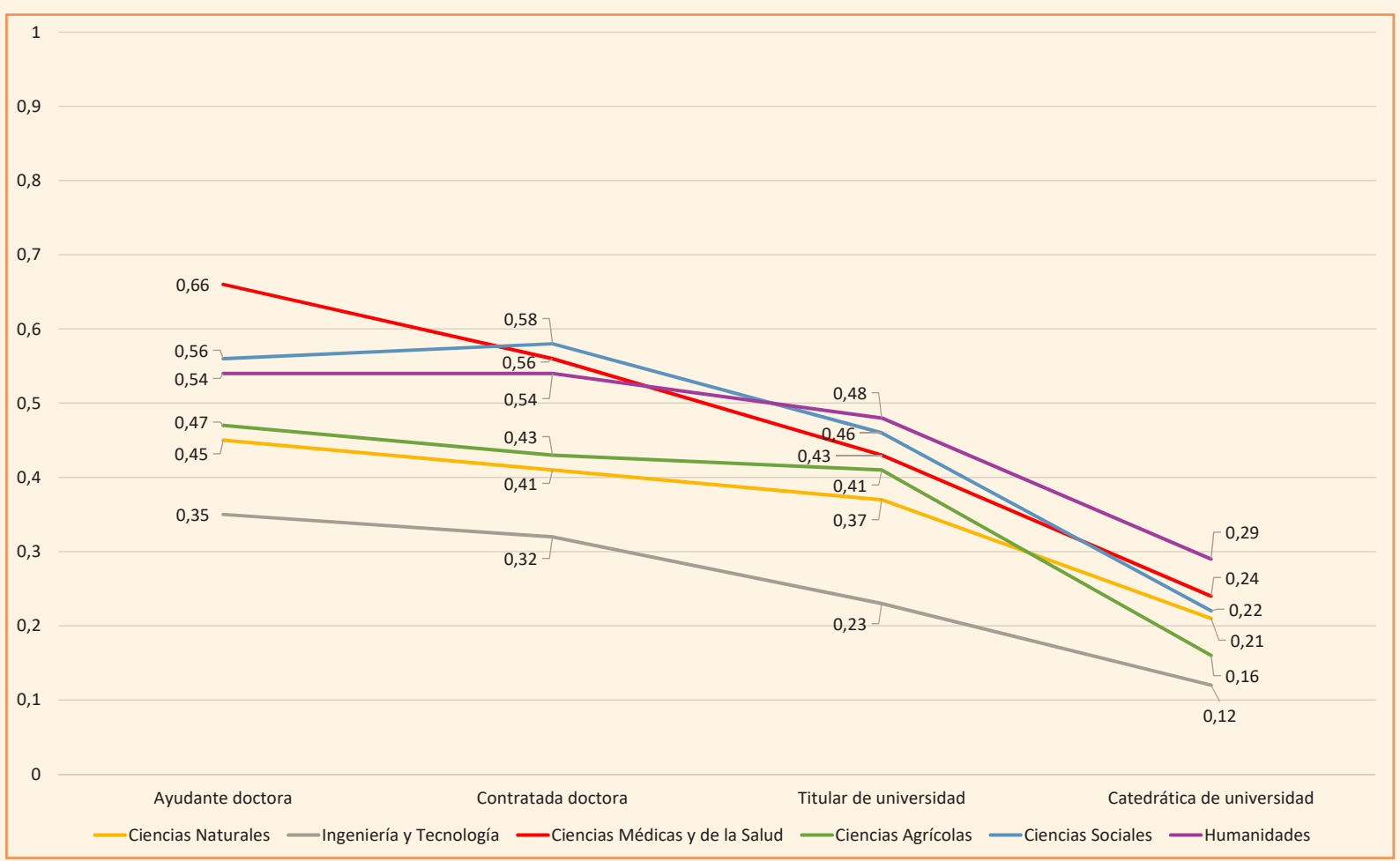

Fuente: Elaboración propia a partir de datos del MCIU (2018, pp. 150-157).

\section{GRÁFICA 3}

PORCENTAJE DE HOMBRES INVESTIGADORES EN EL PDI DE LAS UNIVERSIDADES PÚBLICAS ESPAÑOLAS SEGÚN ÁREA Y CATEGORÍA. CURSO 2016-2017

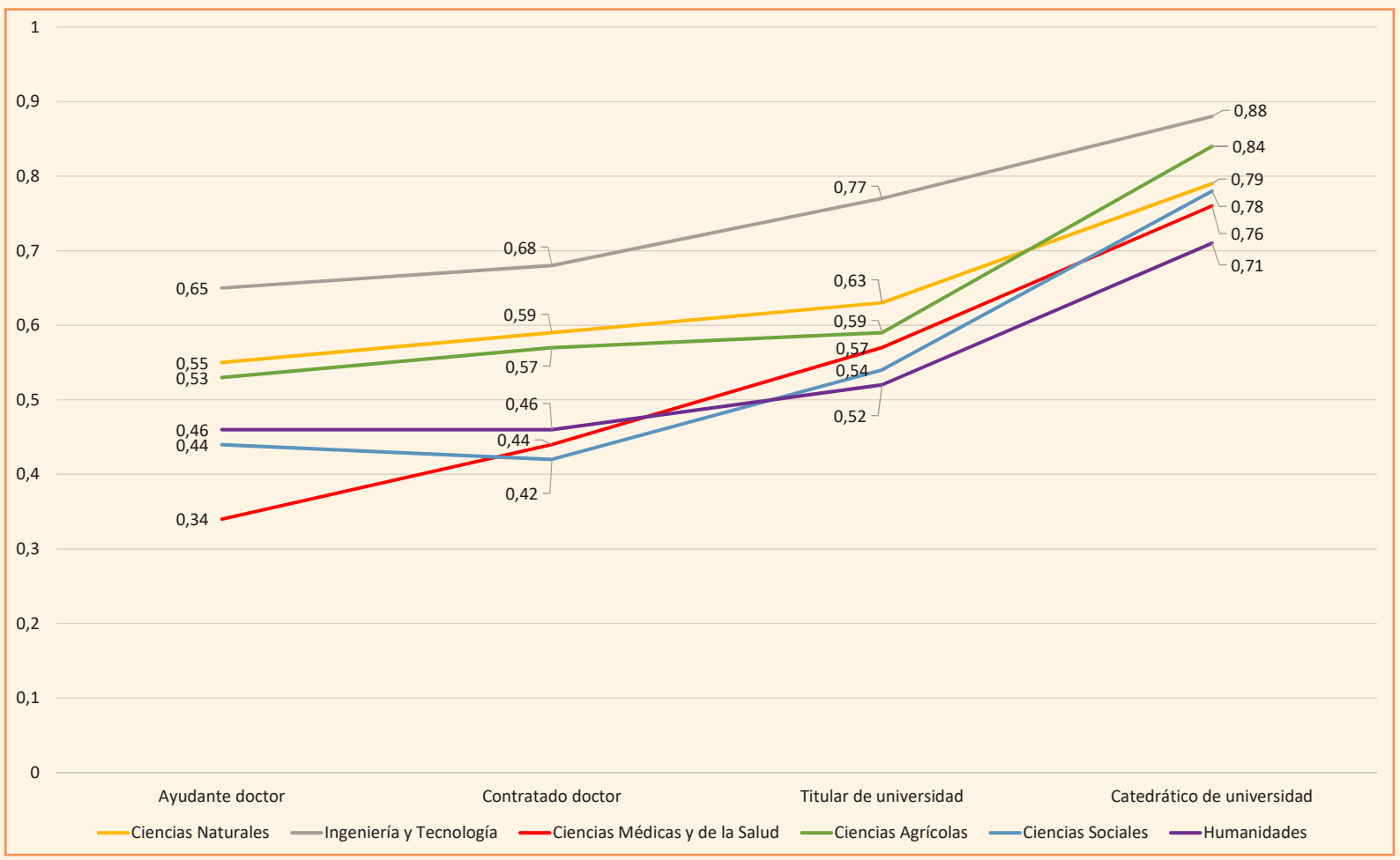

Fuente: Elaboración propia a partir de datos del MCIU (2018, pp. 150-157). 
Pareja a la falta de oportunidades que las mujeres tienen para poder llegar a los puestos más altos de la carrera investigadora, está su exclusión de los cargos de mayor responsabilidad y decisión del organigrama académico (Moncayo Orjuela \& Zuluaga, 2015). Es representativo el caso de la figura de Rector, cuya elegibilidad viene regulada por el art. 20.2 de la Ley Orgánica 6/2001 de Universidades, recogida en el Boletín Oficial del Estado español (Ley Orgánica n. 6, 2001, p. 21), que establece que este solo puede ser elegido de entre el cuerpo de CU. Si partimos de la infrarrepresentación de mujeres como catedráticas -un 21,3\% en España, 2,4 puntos por debajo de la media europea en 2016, según datos de la CE (2019, p. 118)-, exigir que la máxima autoridad académica de la universidad española sea CU supone mantener un obstáculo esencial que aleja a las mujeres de la dirección de las universidades. Por ello, no sorprende que de las 75 personas que ostentan el cargo de Rector/a en el momento de redacción del presente artículo, solo 14 sean mujeres, es decir, un $18,67 \%$ del total. ${ }^{3}$

Por su parte, los círculos de poder masculinos que operan en el espacio público han conseguido que, también en los centros o lugares de producción y difusión del conocimiento, se constituya una sólida red de apoyo y cooptación entre hombres que apuntala la segregación vertical. Este fenómeno, que desde los estudios de género se ha denominado "old boy’s club" (García de León, 1990; Escolano Zamorano, 2006), ahonda en la invisibilización y discriminación de las investigadoras, cuyos perfiles profesionales y proyectos son evaluados en múltiples ocasiones con menor puntuación que en el caso de sus pares masculinos, aun teniendo currículos o propuestas investigadoras de igual o mejor calidad que ellos. ${ }^{4}$ Simultáneamente, debido al "síndrome de la abeja reina" (Staines et al., 1974), las mujeres que se encuentran en los puestos de poder también son susceptibles de incurrir en los mismos prejuicios de género que sus compañeros.

\section{Invisibilización de las investigadoras y del talento femenino}

De la segregación horizontal y vertical que sufren las mujeres investigadoras en España se deducen dos invisibilizaciones primarias: su ausencia tanto de ciertas ramas del conocimiento como de las categorías profesionales y puestos asociados a la estabilidad, el prestigio y el poder. Esta doble omisión tiene consecuencias profundas en el plano personal y laboral, pero también en el orden social y la dimensión simbólica.

En España, las mujeres suponen un 94,5\% del profesorado de educación infantil, un 76,4\% del de educación primaria y un $57,6 \%$ del de educación secundaria. El porcentaje total de mujeres entre el profesorado de enseñanza superior en España es de un 43,4\%, cifra que se debe tomar con cautela por las grandes diferencias internas que existen, según las ramas, dentro de las categorías laborales de docencia universitaria. El alumnado preuniversitario español procede de un sistema escolar feminizado, en el que las profesoras acostumbran ser mayoría, para luego acceder al orden masculinizado de las universidades, donde las investigadoras y docentes quedan relegadas, como hemos visto, a un plano secundario, dinámica esta similar a la lógica general del conjunto de los países de la Organización para la Cooperación y el Desarrollo Económicos (OCDE, 2019, p. 436). Este cambio provoca un alto impacto en la imagen simbólica que se proyecta del talento y saber femeninos como elementos externos a los centros universitarios, espacios tradicionalmente considerados como motores del conocimiento

3 Para dicha estadística se ha tenido en cuenta las 75 universidades españolas, de carácter público y privado, que forman parte de la Crue. La fecha de última revisión de los datos tomados es el 07/07/2020.

4 El sesgo de género se constata como una tendencia global. De Paola y Scoppa (2015) demostraron que en la academia italiana la brecha de género se reduce cuando los órganos decisorios son mixtos y no exclusivamente masculinos. En el contexto estadounidense, Madera et al. (2009) comprobaron que en las cartas de recomendación los hombres son definidos por sus logros y talento innato, mientras que las mujeres se asocian a los cuidados y rasgos comunales; las personas evaluadoras prefieren las referencias del primer tipo. 
intelectual y de los avances científico-tecnológicos. Las mujeres se convierten, así, en la otredad, y es debido a su ausencia de los discursos y prácticas legitimadoras del poder que se consolida todo un intrincado sistema de invisibilizaciones que impiden el ascenso fáctico y simbólico -tanto de ellas como de sus trabajos- al mismo nivel que el de sus pares masculinos.

La ocultación normalizada del talento femenino y de sus aportaciones a lo largo de la historia conlleva en consecuencia la falta de referentes femeninos en todos los ámbitos del saber. Las mujeres no forman apenas parte del catálogo diacrónico y sincrónico de autoridades de cada disciplina: los libros, el aula, los museos, los medios, los certámenes y reconocimientos, el discurso y el espacio públicos, en definitiva, silencian de manera simultánea y perversa sus logros, cuando no se reducen a la anécdota o se paternalizan. Así, la realidad acusa un marcado "androcentrismo académico", aunque en las universidades y otros centros de investigación españoles se enmascare bajo "la ficción de un conocimiento neutral” (Nuño Gómez \& Álvarez Conde, 2017), derivando en la falta de perspectiva de género en las epistemologías y metodologías de todas las disciplinas del conocimiento humano.

Pese a que, teóricamente, en las convocatorias de concurrencia competitiva para la obtención de fondos de investigación se valora de manera positiva la inclusión de perspectiva de género en el estudio, en España solo un 2,08\% del total de las publicaciones realizadas entre 2013 y 2017 la tenían en cuenta. Aunque es una cifra ligeramente superior a la media europea (1,79\%) y mundial (1,66\%), esconde fuertes desigualdades según el área de conocimiento: desde un 4,1\% en Ciencias Sociales hasta un $0,13 \%$ en Ingeniería y Tecnología, lo que demuestra cómo la atención a cuestiones de sexo y/o género todavía no ha sido integrada de forma satisfactoria en las investigaciones estatales (CE, 2019, p. 176).

La entrada en vigor del Plan Bolonia en el sistema universitario español no hizo más que acentuar, en palabras de Nuño Gómez y Álvarez Conde (2017, pp. 284-285), el “. . . capitalismo y androcentrismo académico". Frente a la tendencia que observamos en otros contextos, como el anglosajón, los estudios de género apenas tienen presencia en los grados de las universidades españolas. Actualmente, el único título de grado existente es el de Estudios Socioculturales de Género, de muy reciente creación (2017), que se imparte en la Universitat Autònoma de Barcelona. Se trata del segundo grado sobre género en toda España; el anterior, extinto en el 2014, se impartió durante un breve periodo en la Universidad Rey Juan Carlos. De este modo, en el Estado español la formación en género queda usualmente relegada a la etapa de máster. Asimismo, y de nuevo de manera contraria a lo que ocurre en otros países, en el sistema universitario español no se han creado departamentos específicos en materia de género e igualdad que reconozcan esa especialidad como un área de conocimiento propia, lo que implica unas graves consecuencias en el ámbito tanto curricular como laboral, ya que los departamentos "representan las unidades administrativas donde se aprueba el contenido y la distribución de la docencia y se adoptan las decisiones relativas a la inscripción o defensa de las tesis doctorales o la propuesta de contratación y promoción del profesorado” (Nuño Gómez \& Álvarez Conde, 2017, p. 287).

Por su parte, trabajos internacionales recientes corroboran que el sesgo de género en los sistemas de evaluación científica es una de las más peligrosas y vigentes cortapisas a la promoción del talento femenino en el sector de la investigación. El experimento llevado a cabo por Moss-Racusin et al. (2012) monitorizó cómo eran evaluados por parte del profesorado de las facultades de Biología, Química y Física dos currículos exactamente idénticos, a los que el equipo de investigación atribuyó una única diferencia: el nombre. Así, simularon que uno pertenecía a un estudiante, John, y el otro a una alumna, Jennifer. Los resultados demostraron la presencia de prejuicios de género en la evaluación y selección de candidatos: el profesorado, de ambos sexos, no solo consideró a "Jennifer" menos competente y apta para su contratación que a "John", sino que le ofreció menos oportunidades de tutorización profesional y un salario inferior $(\$ 26.507,94)$ que el de su compañero $(\$ 30.238,10)$. En una línea semejante, el ensayo de Jensen et al. (2018) analizó la tasa de éxito de las patentes presentadas por mujeres, desde 2001, ante la Oficina de Patentes y Marcas de EE. UU (OPM). Mientras que la aparición de nombres femeninos 
reconocibles en la solicitud reducía la posibilidad de éxito -y también drásticamente el número de citas posteriores-, las patentes firmadas por mujeres con nombres infrecuentes eran mucho más citadas que las de sus pares masculinos, lo que demuestra una mayor calidad de los proyectos femeninos.

El sesgo de género en las evaluaciones no es un fenómeno que se de exclusivamente desde la cúpula, sino que también está presente en las bases del sistema. Estudios como el de Boring (2017) y el de Mengel et al. (2019) apuntan que este se produce asimismo en las encuestas de evaluación docente de las que participa el estudiantado, donde las profesoras de las facultades -especialmente las doctorandas- salen peor paradas que sus compañeros, aun cuando no existen patrones objetivos que lo justifiquen. Las consecuencias de este hecho, según Mengel et al. (2019), son el desánimo y falta de autoestima de las investigadoras más jóvenes, que podrían acabar por dejar la carrera académica al no percibir una correlación directa entre su esfuerzo y los resultados obtenidos.

Asimismo, en España y en la UE asistimos a una infrarrepresentación de las investigadoras como autoras de patentes y publicaciones. Al atender a la ratio de mujeres y hombres en patentes de la Clasificación Internacional de Patentes (CIP) en el periodo 2013-2016, constatamos la notoria brecha de género existente en el output científico-tecnológico. Mientras que una cifra cercana al 1 indicaría una relación paritaria entre inventores e inventoras, en España la ratio baja hasta un 0,2, aunque muestra el quinto valor más elevado de la UE, cuya media se sitúa en un 0,1. Con todo, cabe apuntar que el 0,2 español esconde significativas diferencias según la clasificación de la patente, desplomándose a un 0,0 en la sección correspondiente con las patentes relacionadas con Construcciones Fijas y Mecánica, Iluminación, Calefacción, Armamento y Voladura, no habiendo mejorado los indicadores con respecto al periodo 2005-2008 (CE, 2019, pp. 167-169).

También es manifiesta la falta de paridad en la composición de equipos de investigación que presenta patentes. Para el periodo 2013-2016, en la UE han predominado las patentes de equipos formados exclusivamente por hombres (47\%) y las patentes solicitadas por un solo investigador (33\%). En una posición residual quedan las patentes de equipos mixtos, de equipos con al menos un $60 \%$ de investigadoras, de una sola mujer investigadora y, por último, equipos formados exclusivamente por mujeres. Esta tendencia también se repite en España, aunque con resultados que mejoran ligeramente la media europea (CE, 2019, p. 171).

Cuando el baremo tenido en cuenta es el de las contribuciones en autorías, las mujeres también aparecen infrarrepresentadas. España muestra una ratio de 0,55 en el periodo 2013-2017, una cifra que se sitúa a medio camino entre la media europea $(0,67)$ y la mundial $(0,48)$, pero con grandes diferencias según la rama de conocimiento a la que se adscriban las publicaciones, como se aprecia en la Gráfica 4. Las áreas de mayor paridad son las Ciencias de la Salud y las Ciencias Agrícolas (1,0), mientras que Artes y Humanidades muestran los peores resultados $(0,4)$, una tendencia que se asemeja a la europea y a la mundial, en donde también puntúan bajo las Ingenierías y Tecnologías. Con respecto a las autorías fruto de colaboraciones internacionales, europeas y nacionales, las cifras varían, posicionándose peor las investigadoras españolas en las colaboraciones internacionales para el periodo 2013-2017, como podemos ver en la Gráfica 5. 


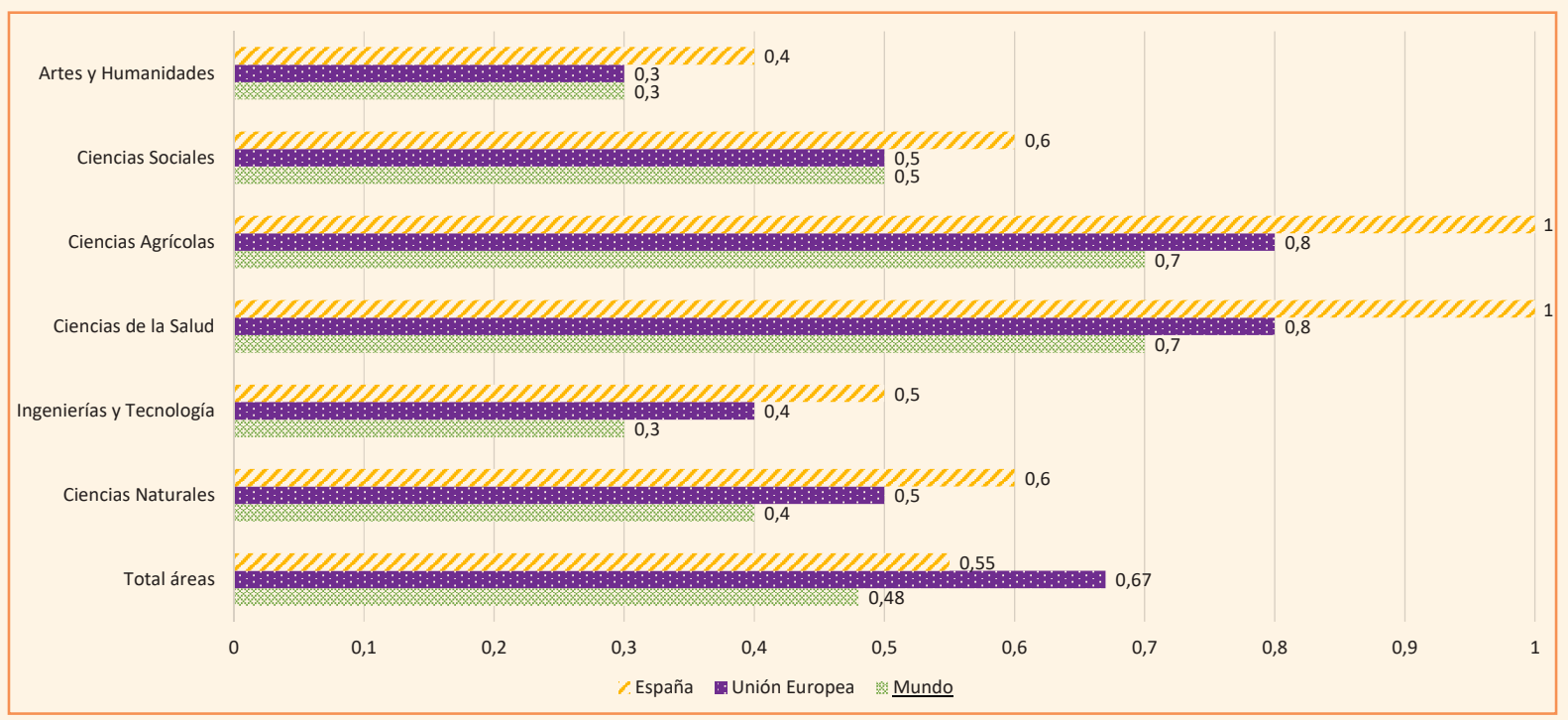

Fuente: Elaboración propia a partir de datos del MCIU (2018, pp. 138-143).

\section{GRÁFICA 5}

RATIO MUJERES - HOMBRES EN EL TOTAL DE AUTORÍAS SEGÚN EL TIPO DE COLABORACIÓN. PERIODO 2013-2017

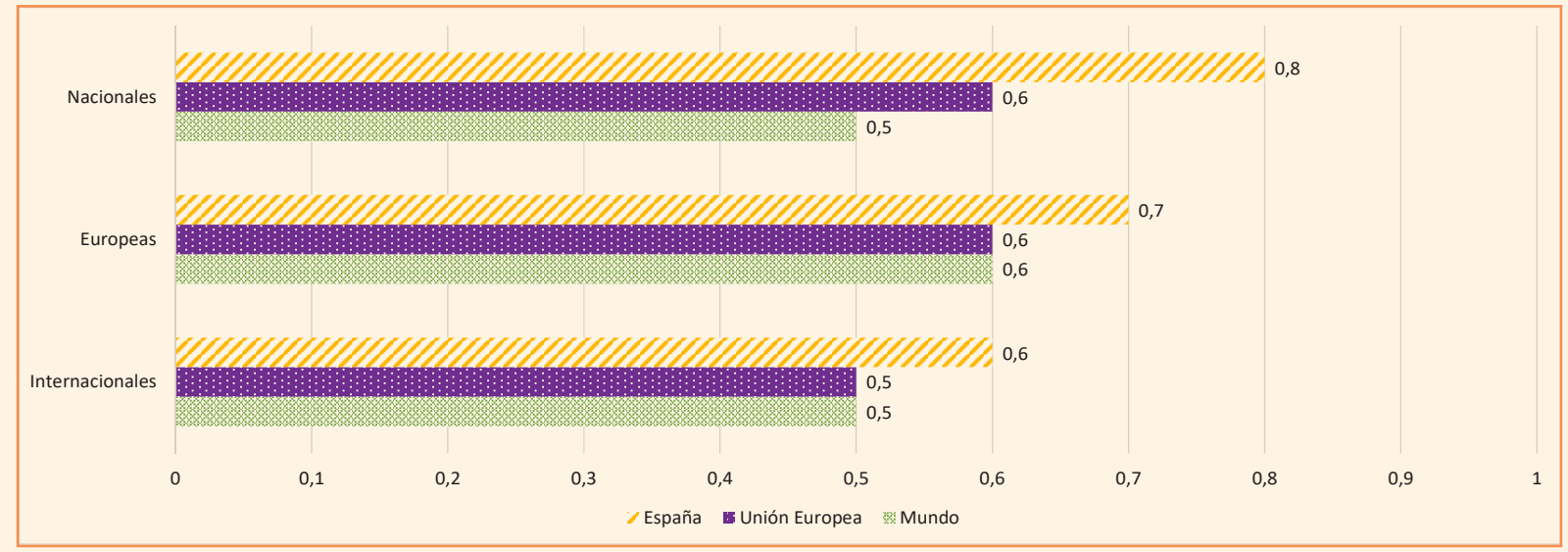

Fuente: Elaboración propia a partir de datos del MCIU (2018, pp. 145-146).

Este hecho resulta llamativo, puesto que las jóvenes investigadoras españolas son las que mayores índices de movilidad internacional muestran en etapa predoctoral, tanto en comparación con sus compañeros españoles como de otros países. Mientras que la media europea muestra que las predoctorales realizan un $1,1 \%$ más de estancias fuera de su país, la media española se dispara a un $32,7 \%$, más del doble que el siguiente país con mayor movilidad de mujeres que de hombres. Sin embargo, a partir de la obtención del título de doctor/a, los hombres pasan a mostrar mayores índices de movilidad exterior, tanto en el caso español como en el europeo, con un 1,8\% y un 3,6\% respectivamente (CE, 2019, pp. 100-101). Si bien la movilidad exterior es vista como una oportunidad para la realización de colaboraciones, el acceso a nuevos equipos de investigación o el aprendizaje de nuevas metodologías, los datos muestran que el salto a la etapa posdoctoral supone para las mujeres una pérdida de competitividad motivada por factores externos a su talento y aportaciones. De hecho, la ratio de hombres y mujeres con relación al impacto de citas ponderadas por campo 
(FWCI, por sus siglas en inglés), a la que hace referencia la Gráfica 6, muestra que los trabajos de autoría femenina y masculina tienen índices de impacto semejantes, no habiendo una disparidad en función del sexo claramente identificable. ${ }^{5}$

\section{GRÁFICA 6}

\section{RATIO MUJERES - HOMBRES EN FWCI SEGÚN ÁREA DE CONOCIMIENTO. AÑO 2017}

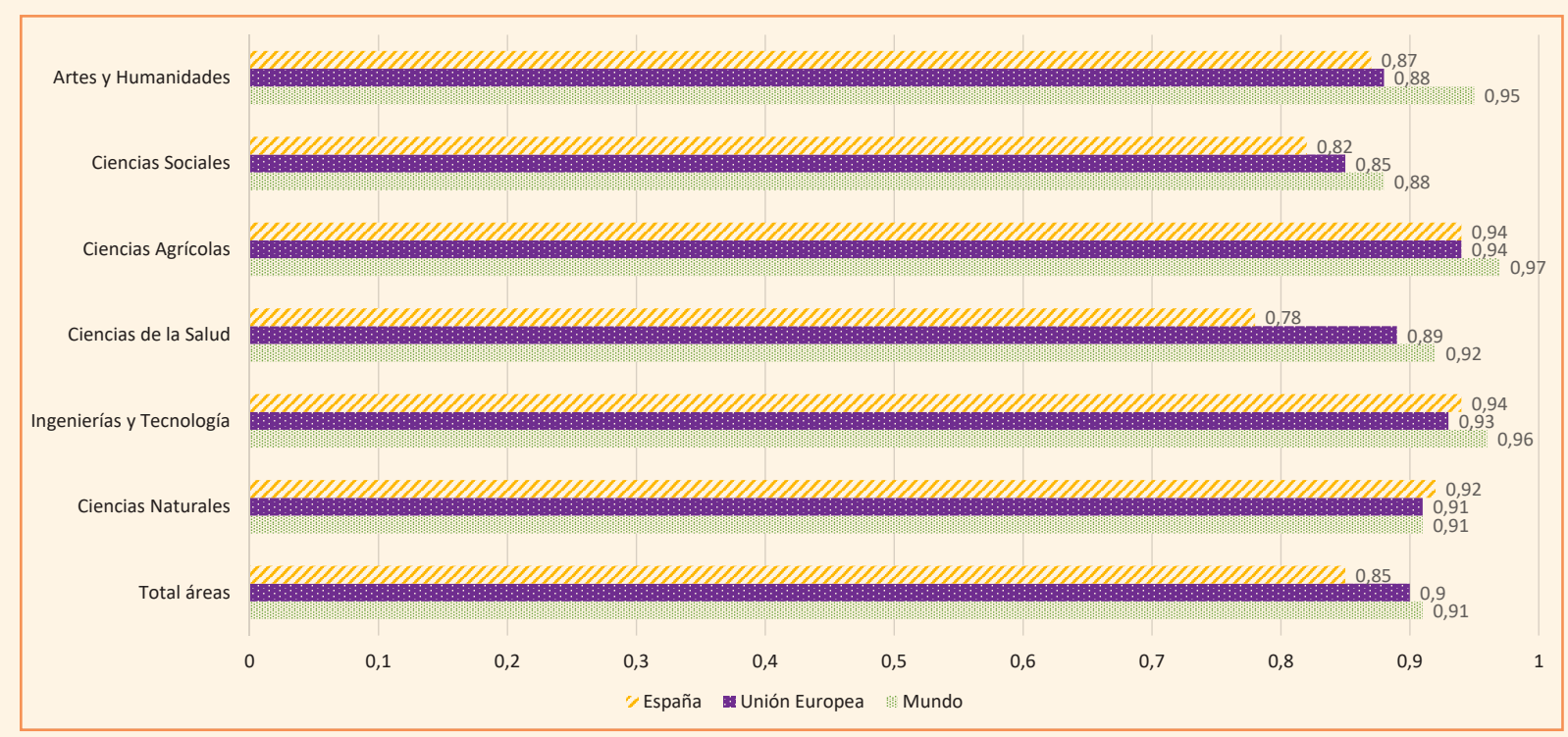

Fuente: Elaboración propia a partir de datos del MCIU (2018, pp. 155-159).

Dado que la transferencia de conocimiento a través de publicaciones y patentes es uno de los méritos más evaluables para ascender en el escalafón académico, las mujeres tienen menos posibilidades de obtener fondos de investigación para sus proyectos y, por tanto, de convertirse en Investigadoras Principales (IPs), operando así de forma conjunta la invisibilización de su trabajo con el techo de cristal. Es reveladora la tasa de éxito según el sexo de las personas solicitantes en las ayudas adscritas dentro de los principales programas del Plan Estatal de Investigación Científica y Técnica y de Innovación (2013-2016), en los que los investigadores varones muestran valores más altos de éxito en la obtención de fondos, con diferencia de hasta 8 puntos con respecto a sus compañeras (MCIU, 2018, p. 117). ${ }^{6}$ Por otra parte, el informe Mujeres e Innovación 2020 del Observatorio de Mujeres, Ciencia e Innovación (OMCI, 2020, p. 70) apunta que las investigadoras españolas, además de lograr menos proyectos que los hombres, también obtienen cuantías inferiores, lo que precariza más su trabajo.

\section{Ampliando el horizonte de la precariedad: brecha salarial, temporalidad y dificultad para conciliar}

La precariedad profesional que planea sobre las investigadoras de España también está íntimamente ligada con la precariedad personal. Dentro del sector de $\mathrm{I}+\mathrm{D}+\mathrm{i}$, la exclusión de las mujeres de puestos de poder y responsabilidad acentúa la brecha salarial por razón de género, ya que las mujeres están atrapadas en las categorías laborales más bajas, con mayor grado de temporalidad y peor remuneración que sus colegas hombres. Además, hay que tener en cuenta los complementos salariales derivados de

5 Aun así, en el plano individual existen notables diferencias en el tratamiento de las investigaciones según el sexo. King et al. (2017) comprobaron que los investigadores autocitan sus trabajos previos un 70\% más que las mujeres.

6 España es el sexto país de la UE en el que los hombres tienen mayores tasas de éxito a la hora de conseguir fondos públicos de investigación, muy lejos de Alemania, Noruega y Portugal, donde se aprecia una paridad entre mujeres y hombres para dicho parámetro. 
estar en la cúspide de la carrera investigadora, cuyo carácter no reglado acentúa la brecha salarial entre el PDI. La existencia de este tipo de retribuciones en apariencia libres, pero en definitiva condicionadas por factores socioculturales e institucionales, implica "aceptar grietas por donde se colarían formas sutiles e invisibles de discrecionalidad, en concursos, posibilidades de formación, en el trato, en la asignación generizada de tareas, en las posibilidades de participación en proyectos de investigación o en publicaciones, entre otras" (Jabbaz et al., 2019, p. 2).

En las últimas décadas hemos asistido a una pauperización de la carrera investigadora, caracterizándose por la inseguridad laboral, la temporalidad y la movilidad constante. Es esta una cuestión tan preocupante que incluso la CE la ha recogido como uno de sus barómetros en el informe She Figures. Según el mismo, en 2016 algo más del 13\% del personal investigador europeo estaba trabajando en instituciones de enseñanza superior con contratos temporales. Por sexo, las mujeres investigadoras fueron las más afectadas por la precariedad, con un $8,1 \%$ de temporalidad frente al 5,2\% de sus colegas varones. Cuando el parámetro tenido en cuenta es la dedicación a media jornada, también ellas mostraron cotas más elevadas, con un $13 \%$ y un $8 \%$ respectivamente. En el caso español, se aprecia una anomalía respecto de la tónica general europea, ya que son los hombres los que alcanzan porcentajes mayores en sendas métricas, con un 10,4\% de precariedad y un 5,8\% de parcialidad, mientras que las investigadoras españolas se situaron en un 7\% y un 3\% (CE, 2019, pp. 97-99). Aunque el informe destaca que las posiciones junior y los contratos que dependen de una financiación de terceros son los más afectados por la precariedad, a falta de mayores detalles sobre estas estadísticas -como desagregar los datos por categoría laboral o edad-, consideramos que la explicación para la irregularidad española con respecto a la media europea puede residir en el hecho de que, como hemos explicado, a partir de la defensa de la tesis doctoral, las investigadoras en España tienen mayores dificultades para encontrar su hueco en el organigrama académico, por lo que su presencia en él es menor que en otros países. Así, la precariedad se convierte, paradójicamente, en un elemento más de invisibilización femenina.

Otro elemento de pauperización en el que España sí sigue la tendencia europea es la brecha salarial. Pese a que la igualdad retributiva entre hombres y mujeres es uno de los principios fundamentales de los tratados de la UE, en casi todos los países las mujeres que se dedican a la $\mathrm{I}+\mathrm{D}+\mathrm{i}$ ganan menos que sus compañeros, siendo la brecha salarial incluso un poco más ancha que en el total de la economía (CE, 2019 , p. 102). En resumidas cuentas, se puede afirmar que por cada euro que gana un investigador, una investigadora apenas recibe 83 céntimos. 


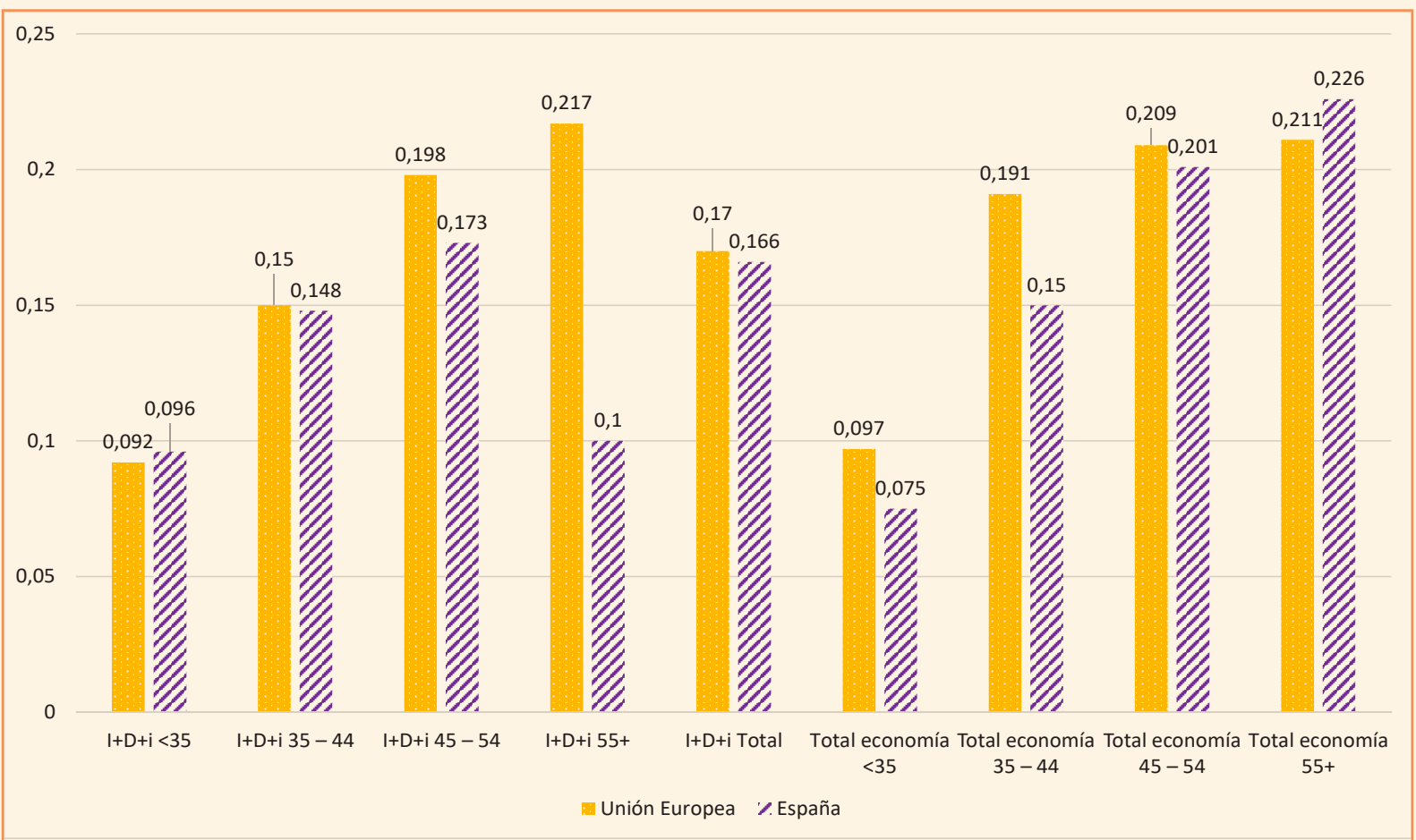

Fuente: Elaboración propia a partir de datos de la CE (2019, pp. 155-159).

Para una mayor aproximación a la brecha salarial en el caso de las universidades españolas, podemos acudir al trabajo de Jabbaz et al. (2019). En él se demuestra la existencia de brecha salarial de género entre el PDI de la Universitat de València durante el año 2015, tomando como muestra de estudio las categorías laborales más altas $(\mathrm{AD}, \mathrm{CD}, \mathrm{TU}$ y $\mathrm{CU})$, por ser precisamente estas figuras las que implican una mayor cualificación y porque su salario está regulado mediante una normativa específica. La brecha salarial de género está presente en todas ellas, aunque la más alta se da en la figura TU: una brecha de 3,99\% que "implica que las mujeres de esta categoría perciben en promedio 1,05€ menos que sus homólogos masculinos por cada hora remunerada". La más baja, por su parte, se produce entre el PDI que es AD (1,39\%), debido a que optan a menos complementos salariales de carácter discrecional que el personal consolidado: esta categoría no puede solicitar sexenios, su contratación se reduce a un máximo de 5 años y no dispone de antigüedad ni puede acceder a otros pluses (Jabbaz et al., 2019, p. 12).

El techo de cristal, el sesgo de género y las redes de apoyo y cooptación masculinas son tres importantes razones que influyen en las diferencias salariales entre hombres y mujeres dentro de la universidad española. En el mundo de la investigación, los bienes materiales acostumbran a ir ligados a bienes simbólicos, y los investigadores acaparan ambos tipos (Jabbaz et al., 2019, p. 6). Asimismo, existe consenso a la hora de identificar el tiempo dedicado a los cuidados - a menores, mayores, personas dependientes, tareas del hogar...-, que también es asumido de manera desigual entre uno y otro sexo, como un motivo más de la expulsión gradual del sistema de $\mathrm{I}+\mathrm{D}+\mathrm{i}$ que sufren las mujeres en España. Según información extraída de la base de datos del Instituto Nacional de Estadística (INE), ${ }^{7}$ en el año 2016 las mujeres en España dedicaron una media de 38 horas a la semana al cuidado o educación de 
sus hijos/as, 20 horas al cuidado de familiares, vecinos/as o amigos/a enfermos/as y de personas con discapacidad menores de 75 años y 18 horas semanales al cuidado de las personas que superan los 75 años -frente a las 23, 14 y 14 horas dedicadas por los hombres, respectivamente-. Asimismo, el trabajo doméstico sigue estando desigualmente repartido: las mujeres de España ocupan 20 horas semanales en este tipo de tareas y los hombres solo 11, mientras que estos dedican unos 50 minutos más al día que ellas a actividades de ocio (Montes López, 2017, p. 225).

La falta de corresponsabilidad y de medidas efectivas para la conciliación laboral y personal afecta en mayor medida a las investigadoras que a los investigadores. Los testimonios de las personas que se dedican a la investigación acostumbran a poner énfasis en la cantidad de tiempo personal que consumen, fuera de su jornada oficial de trabajo, para poder avanzar en sus investigaciones y así seguir manteniendo un ritmo competitivo con el que puedan aspirar a promocionar dentro de la profesión, que consideran una carrera de fondo en la que no existe el descanso, y que se puede acabar por completo si existen personas al cargo que cuidar -especialmente, hijos/as-, sobre todo si esto ocurre en una fase en la que la posición académica todavía no está consolidada (Montes López, 2017). Teniendo en cuenta que la entrada en el funcionariado universitario se consigue con la plaza de TU y que, según el catálogo de datos del MCIU (2020), durante el curso 2018-2019 la edad media del PDI funcionario se situó en los 55 años, se dilucida que la maternidad puede suponer un punto de inflexión en las carreras de muchas investigadoras. Durante el curso 2015-2016, el grupo de mujeres PDI más numeroso fue el menor de 30 años (58,3\%), una cifra que desciende al 55,3\% para el grupo comprendido entre 30 y 34 años, y al 47,8\% cuando llegamos a la franja comprendida entre 35 y 39 años. Si partimos de la base de que, en España, la edad media de la maternidad se sitúa en los 32 años (INE, 2019, p. 10), semeja que el abandono de las investigadoras del sistema de I+D+i español tiene relación directa con las dificultades para conciliar su vida laboral y personal, pero también con los prejuicios de género y con las barreras sociales e institucionales que sufren a raíz de su elección de maternidad (Chinchilla et al., 2017).

Generalmente, las mujeres que son madres experimentan diferentes cortapisas para promocionar en sus carreras y sentirse bien en sus puestos: pueden sufrir el aislamiento por parte de sus compañeros de trabajo y comentarios sexistas y despectivos acerca de su valía, a menudo se les ofrecen menos oportunidades laborales - a veces, por miedo a que se queden de nuevo embarazadas y la productividad del equipo se resienta- y, cuando esto ocurre, las ofertas profesionales acostumbran tener salarios más bajos que antes de la maternidad. Este fenómeno, que se produce de manera global, es conocido como "pena de maternidad" (motherhood penalty) (Correll et al., 2007), y se contrapone a la "prima de paternidad" (fatherhood premium) (Killewald, 2012) que experimentan los hombres, cuyas carreras son en ocasiones impulsadas una vez que son padres. En el ámbito específico de la investigación, también existen estudios que demuestran que la pena de maternidad es una de las causas de abandono y de expulsión de las investigadoras de los sistemas internacionales de I+D+i (Preston, 2004; Henley, 2015). Para el caso español, el Libro Blanco. Situación de las mujeres en la Ciencia Española (Sánchez de Madariaga, 2011, p. 12) ya constató que la tenencia de hijos/as influía de manera desigual en la promoción del personal investigador: con el mismo currículum, un hombre con descendencia tiene una probabilidad 4 veces mayor de ser promocionado a catedrático que una mujer con el mismo perfil laboral y personal, por ejemplo. El hecho de que las investigadoras de España se sigan ocupando mayoritariamente de los cuidados “. . compite, en la práctica cotidiana, con el tiempo necesario para el mantenimiento de redes informales y con las estancias de investigación en centros extranjeros", actividades fundamentales para la carrera académica (Jabbaz et al., 2019, p. 6). 


\section{Conclusiones}

Bourdieu (2000, p. 117) ya identificó hace tiempo tres causas principales para la segregación sexuada de las carreras y puestos. En su opinión, las dos primeras tenían que ver con que se siguiese entendiendo que "las funciones adecuadas para las mujeres son una prolongación de las funciones domésticas: enseñanza, cuidado, servicio", y que el hombre dispusiese "del monopolio de la manipulación de los objetos técnicos y las máquinas”. Ambas razones han sido presentadas en este trabajo al analizar la relevancia todavía vigente de los estereotipos de género y su influencia en el reparto sexuado de las disciplinas del conocimiento en el ámbito de la $\mathrm{I}+\mathrm{D}+\mathrm{i}$. El sociólogo ofrecía también una tercera causa, con la que interrelacionaba los motivos de la segregación horizontal con la vertical al afirmar que "una mujer no puede tener autoridad sobre unos hombres, y tiene, por tanto, todas las posibilidades . . . de verse postergada por un hombre en una posición de autoridad y de verse arrinconada a unas funciones subordinadas de asistencia”. A lo largo del artículo, se ha pretendido demostrar que este techo de cristal que relega a las mujeres a la subordinación se relaciona muy de cerca con la invisibilización que las sitúa en posiciones de alteridad. El androcentrismo epistemológico que atraviesa la educación española, en todos sus niveles, resulta todavía más peligroso en la etapa universitaria, cuando la presencia -simbólica y fáctica- tan marcada de los hombres dentro de los centros de investigación y docencia actúa a la vez que "la hegemonía masculina de los lugares de decisión política y económica", lo que naturaliza "la jerarquización sociosexuada de los saberes y las prácticas profesionales", tanto como se acaba proyectando la imagen, entre el alumnado, de que el saber femenino es un saber elemental, mientras que el masculino es un tipo de saber complejo (Marrero, 2006, p. 65). Por su parte, se destacó que la invisibilización del talento femenino y el techo de cristal operan, junto con otros factores como el sesgo de género, las redes de cooptación masculinas o la pena de maternidad, a la hora de aumentar la brecha salarial de género dentro de la educación superior española.

Ante este panorama, parece evidente que en España necesitamos un cambio legislativo efectivo con el que evitar discriminaciones y desigualdades por razón de género, pero aún más un sistema de control y penalizaciones que actúe sobre las entidades e instituciones que incumplan las medidas de igualdad y conciliación amparadas por la ley. Después de décadas de recomendaciones basadas en el buenintencionismo para revertir la discriminación sexuada contra las mujeres, la situación en la que se encuentran -tanto en el sistema académico como en la sociedad-apenas ha mejorado, o lo hace muy lentamente. Consideramos, además, que el verdadero cambio deberá ir acompañado también de una transformación socioeducativa que opere desde las bases del propio sistema, para que la aplicación de la perspectiva de género y la erradicación de conductas y prejuicios sexistas atraviese todos los niveles de la educación española y consiga calar en nuestra sociedad de manera duradera y consolidada.

\section{Agradecimientos}

Aldara Cidrás ha realizado la investigación con la cofinanciación de la Xunta de Galicia a través de los fondos del "Programa de axudas á etapa predoutoral 2018" de la Consellería de Cultura, Educación e Ordenación Universitaria y la agencia de innovación Gain de la Consellería de Economía, Emprego e Industria dependientes de dicha entidad.

\section{Referencias}

Bian, L., Leslie, S. J., \& Cimpian, A. (2017). Gender stereotypes about intellectual ability emerge early and influence children's interests. Science, 355(6326), 389-391.

Boring, A. (2017). Gender biases in student evaluations of teachers. Journal of Public Economics, 145(C), 27-41. 
Bourdieu, P. (2000). La dominación masculina (J. Jordá, Trad.). Anagrama.

Chinchilla, N., Jiménez, E., \& Grau M. (2017). Maternidad y trayectoria profesional en España: Análisis de las barreras e impulsores para la maternidad de las mujeres españolas. IESE Business School.

Comisión Europea . (2019). She Figures 2018. Oficina de Publicaciones de la Unión Europea. https://ec.europa. eu/info/publications/she-figures-2018_en

Conferencia de Rectores de las Universidades Españolas . (2019). La universidad española en cifras: 2017/2018. Crue.

Correll, S., Bernard, S., \& Paik, I. (2007). Getting a Job: Is there a motherhood penalty? American Journal of Sociology, 112(5), 1297-1339.

De Paola, M., \& Scoppa, V. (2015). Gender discrimination and evaluators' gender: Evidence from the Italian academia. Economica, 82, 162-188.

Escolano Zamorano, E. (2006). Discriminación en un medio meritocrático: Las profesoras en la universidad española. Revista Mexicana de Sociología, 68(2), 231-266.

García de León, M. A. (1990). Las profesoras universitarias: El caso de una élite discriminada. Revista Complutense de Educación, 1(3), 355-372.

Henley, M. (2015). Women's success in academic science: Challenges to breaking through the Ivory Ceiling. Sociology Compass, 9(8), 668-680. https://doi.org/10.1111/soc4.12291

Hymowitz, C., \& Schellhardt, T. (1986). The Glass-Ceiling: Why women can't seem to break the invisible barrier that blocks them from top jobs. The Wall Street Journal, 57, D1, D4-D5.

Instituto Nacional de Estadística. (2019). España en cifras 2019. https://www.ine.es/prodyser/espa_ cifras/2019/12/

Jabbaz, M., Samper Gras, T., \& Díaz, C. (2019). La brecha salarial de género en las instituciones científicas: Estudio de caso. Convergencia: Revista de Ciencias Sociales, (80), 1-27.

Jensen, K., Kovács, B., \& Sorenson, O. (2018). Gender differences in obtaining and maintaining patent rights. Nature Biotechnology, 36(4), 307-309. https://doi.org/10.1038/nbt.4120

Killewald, A. (2012). A reconsideration of the fatherhood premium: Marriage, coresidence, biology, and fathers. Wages. American Sociological Review, 78(1), 96-116. https://doi.org/10.1177/0003122412469204

King, M., Bergstrom, C., Correll, S., Jacquet, J., \& West, J. (2017). Men set their own cites high: Gender and self-citation across fields and over time. Socius: Sociological Research for a Dynamic World, 3, 1-22.

Ley Orgánica n. 6, de 21 de diciembre de 2001. (2001). Universidades. Boletin Oficial del Estado - BOE n. 307. https://www.boe.es/buscar/pdf/2001/BOE-A-2001-24515-consolidado.pdf

López Sáez, M. (1995). La elección de una carrera típicamente femenina o masculina desde una perspectiva psicosocial: La influencia del género. Ministerio de Educación y Ciencia.

Madera, J., Hebl, M. R., \& Martin, R. C. (2009). Gender and letters of recommendation for academia: Agentic and communal difference. Journal of Applied Psychology, 94(6), 1591-1599. https://doi.org/10.1037/ a0016539

Marrero, A. (2006). El asalto femenino a la universidad: Un caso para la discusión de los efectos reproductivos del sistema educativo en relación al género. Revista Argentina de Sociología, 4(7), 47-69.

Martín Asensio, U., Montes López, E., \& Groves, T. (2015). “Me lo tengo que currar más”: Las docentes en la Facultad de Bellas Artes de la Universidad de Salamanca en sus 30 años de historia. In J. Cuesta Bustillo, M. L. de Prado Herrera, \& F. Rodríguez Jiménez (Coord.), ¿Mujeres sabias?: Mujeres universitarias en España y América Latina (pp. 373-394). Presses Universitaires de Limoges.

Mengel, F., Sauermann, J., \& Zölitz, U. (2019). Gender bias in teaching evaluations. Journal of the European Economic Association, 17(2), 535-566. https://doi.org/10.1093/jeea/jvx057

Ministerio de Ciencia, Innovacion y Universidades. (2018). Cientificas en Cifras 2017: Estadisticas e indicadores de la (des)igualdad de género en la formación y profesión cientifica. MCIU; Unidad de Mujeres y Ciencia. https://www.ciencia.gob.es/stfls/MICINN/Ministerio/FICHEROS/UMYC/Cientificas_ cifras_2017.pdf 
Ministerio de Ciencia, Innovacion y Universidades. (2020). Catálogo de datos. https://www.ciencia.gob.es/ portal/site/m.26172fcf4eb029fa6ec7da6901432ea0/?vgnextoid=76dddd449de8b610VgnVCM1000 001d04140aRCRD

Moncayo Orjuela, B. C., \& Zuluaga, D. (2015). Liderazgo y género: Barreras de mujeres directivas en la academia. Pensamiento \& Gestión, (39), 142-177.

Montes López, E. (2017). La ausencia de corresponsabilidad, freno para el desarrollo de la carrera laboral femenina en la Academia. Feminismo/s, (29), 221-242. https://doi.org/10.14198/fem.2017.29.09

Moss-Racusin, C., Dovidio, J. F., Brescoll, V. L., Graham, M. J., \& Handelsman, J. (2012). Science faculty's subtle gender biases favor male students. PNAS, 109(41), 16474-16479. https://doi.org/10.1073/ pnas. 1211286109

Navarro Guzmán, C., \& Casero Martínez, A. (2012). Análisis de las diferencias de género en la elección de estudios universitarios. Estudios Sobre Educación, 2, 115-132.

Nuño Gómez, L., \& Álvarez Conde, E. (2017). Androcentrismo académico: La ficción de un conocimiento neutral. Feminismo/s, (29), 279-297. https://doi.org/10.14198/fem.2017.29.11

Observatorio de Mujeres, Ciencia e Innovación. (2020). Mujeres e innovación 2020. OMCI. https://www. ciencia.gob.es/stfls/MICINN/Ministerio/FICHEROS/Publicaciones/AF_Mujeres-e-innovacion_ web.pdf

Organización para la Cooperación y el Desarrollo Económicos. (2019). Education at a Glance 2019: OECD Indicators. OECD Publishing. https://doi.org/10.1787/f8d7880d-en

Pérez, F., \& Aldás, J. (Dir.). (2020). U-Ranking 2020: Indicadores sintéticos de las universidades españolas. Fundación BBVA-IVIE. https://www.fbbva.es/wp-content/uploads/2020/06/Informe-U-RankingFBBVA-Ivie-2020.pdf

Preston, A. (2004). Leaving science. Russel Sage Foundation.

Sabater, C. (2014). La interacción trabajo-familia: La mujer y la dificultad de la conciliación laboral. Lan Harremanak: Revista de Relaciones Laborales, (30), 163-198.

Sáinz Ibáñez, M., \& Meneses, J. (2018). Brecha y sesgos de género en la elección de estudios y profesiones en la educación secundaria. Panorama Social, (27), 23-31.

Sáinz Ibáñez, M., \& Müller, J. (2017). Gender and family influences on Spanish students' aspirations and values in stem fields. International Journal of Science Education, 40(2), 88-203. https://doi. org/10.1080/09500693.2017.1405464To

Sánchez de Madariaga, I. (2011). Libro blanco: Situación de las mujeres en la ciencia española. Unidad de Mujeres y Ciencia. https://www.ciencia.gob.es/stfls/MICINN/Ministerio/FICHEROS/UMYC/ LibroBlanco_Interactivo.pdf

Sistema Universitario de Información Universitaria. (2019). Indicadores universitarios de rendimiento académico. Curso 2017-2018. https://www.ciencia.gob.es/stfls/MICINN/Universidades/Ficheros/Estadisticas/ Nota-Estadistica-de-Indicadores-Rendimiento-2019.pdf

Staines, G. L., Tavris, C., \& Jayaratne, T. E. (1974). The queen bee syndrome. Psychology Today, 7(5), 55-60.

Subirats Martòri, M., \& Brullet Tenas, C. (1988). Rosa y azul: La transmisión de los géneros en la escuela mixta. Instituto de la Mujer.

Torres González, O., \& Pau, B. (2011). Techo de cristal y suelo pegajoso: La situación de la mujer en los sistemas alemán y español de ciencia y tecnología. CTS: Revista Iberoamericana de Ciencia, Tecnología y Sociedad, 6(18), 35-59. 
Nota sobre la autoría

Las autoras participaron por igual en la elaboración y revisión del artículo.

Disponibilidad de datos

Los contenidos subyacientes al texto de la investigación están contenidos en el manuscrito.

\section{Cómo citar este artículo}

Cidrás, A., \& Camino Plaza, L. (2021). Cuestión de género: La discriminación de las investigadoras en España. Cadernos de Pesquisa, 51, Artículo e07641. https://doi.org/10.1590/198053147641 